\title{
Unilateral fronto-temporal headache with ocular pain caused by lens subluxation due to spontaneous zonulysis
}

\author{
Taejin Park, Gyuman Choi \\ Department of Emergency Medicine, National Medical Center, Seoul, Korea
}

\begin{abstract}
A 52-year-old man presented to the emergency department (ED) for left frontotemporal headache and left eye pain. In the ED, visual exam with extra-ocular movement was performed to rule out ocular pathology and brain imaging to rule out cerebral pathology. No abnormal finding was noted after evaluation of ED. Initial exam by an ophthalmologist was also negative with normal intraocular pressure. Left lens dislocation was found only after brain imaging. In subsequent second exam by an ophthalmologist with iridodilator, lens dislocation due to spontaneous zonulysis was finally confirmed. Hence, ED physicians should carefully review ocular as well as brain anatomy in such cases.
\end{abstract}

Keywords Lens subluxation; Spontaneous zonulysis; Headache; Ocular pain
What is already known

Lens subluxation and dislocation can be caused by trauma or systemic disease. Trauma is the most common cause of lens dislocation, but it has also been reported in systemic diseases such as Marfan syndrome, homocystinuria, and Weill-Marchesani syndrome.

What is new in the current study

Our case was lens subluxation due to spontaneous zonulysis, a very unusual presentation.
elSSN: 2383-4625

Received: 30 March 2015

Revised: 30 April 2015

Accepted: 4 May 2015

Correspondence to: Taejin Park Department of Emergency Medicine, National Medical Center, 245 Eulji-ro, Jung-gu, Seoul 100-799, Korea E-mail: nmcemergency@gmail.com

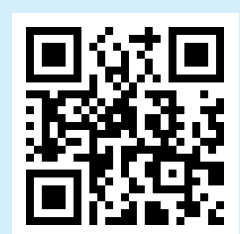

How to cite this article:

Park T, Choi G. Unilateral fronto-temporal headache with ocular pain caused by lens subluxation due to spontaneous zonulysis. Clin Exp Emerg Med 2015;2(2):133-136.

This is an Open Access article distributed under the terms of the Creative Commons Attribution Non-Commercial License (http:// creativecommons.org/licenses/by-nc/3.0/). 


\section{INTRODUCTION}

Unilateral headache with orbital pain is a common presenting symptom of several ocular and neurologic complication, and should be differentially diagnosed in the emergency department (ED). Ocular pathology can cause headaches and cerebral pathology can cause ocular pain. Hence, the brain and the eyes should be subjected to a detailed examination.

Herein, we review to our knowledge, the first case of unilateral fronto-temporal headache with ocular pain caused by spontaneous lens dislocation due to zonulysis. Lens dislocation (ectopia lentis) refers to a displacement of the lens from its normal position. The lens may be completely dislocated, rendering the pupil aphakic (luxated), or partially displaced, still remanding in the pulpillary area (subluxated). Spontaneous dislocation of a clear lens is rare.

\section{CASE REPORT}

A 52-year-old male patient, who had been experiencing left fronto-temporal headache with left ocular pain for 1 day, was admitted to the ED. The day before admission, the man had experienced headache and ocular pain for 3 hours, and then recovered spontaneously. On the day of admission, the symptoms had recurred

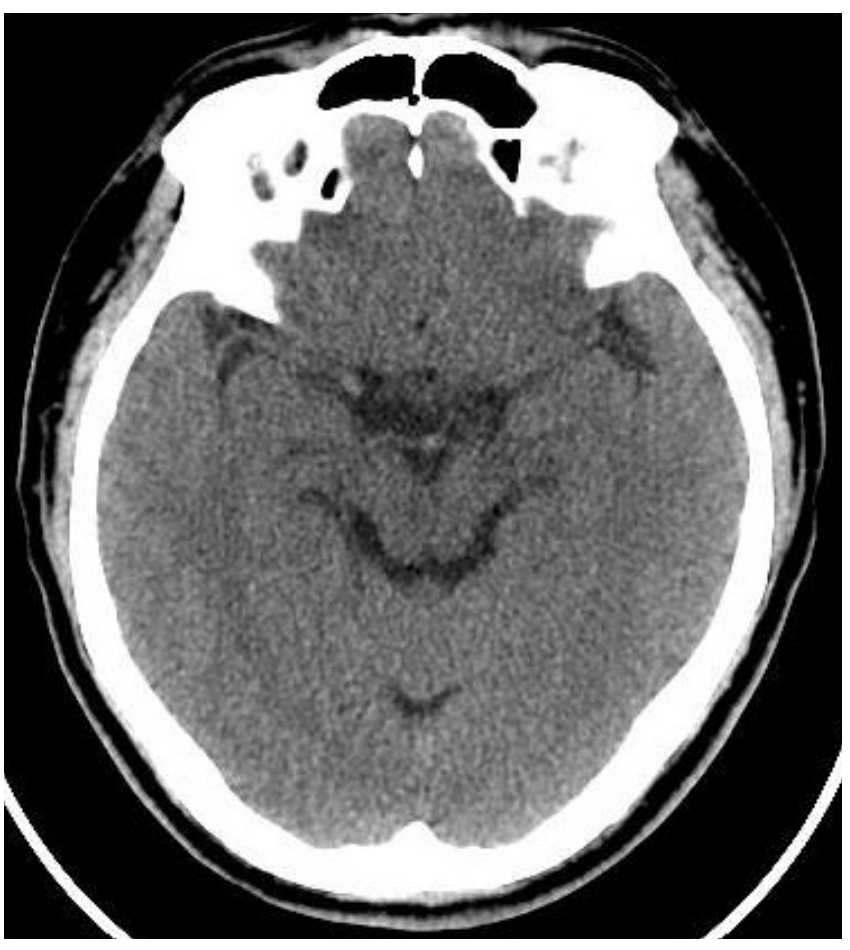

Fig. 1. Absence of acute brain parenchymal lesion upon initial computed tomography of the brain. abruptly and persisted. The headache was dull, and ocular pain was more severe in the lean-forward position. He also complained of blur red vision and lacrimation in the left eye in the supine position. The headache had occurred spontaneously without any history of trauma. He has no past medical history without hypertension.

The patient's vital signs at the time of admission into the ED were as follows: blood pressure, 170/105 mmHg; heart rate, 68 beats/min; respiratory rate, 18 breaths/min; body temperature $36.1^{\circ} \mathrm{C}$. His mental status was clear. Ophthalmologic examination revealed normal visual field, extra-ocular movement and light reflex. Laboratory findings were unremarkable. To rule out brain lesion, we performed computed tomography (CT) of the brain. No parenchymal lesion or bony deformity was seen in the brain (Fig. 1).

Consult to neurologist and ophthalmologist was done due to rule out cluster headache and glaucoma. Neurologist ordered brain magnetic resonance angiography (MRA) of the brain to rule out cavernous carotid fistula. The results were normal (Fig. 2). Neurologist requested ophthalmologist consult.

The initial ophthalmologic examination revealed normal findings, including normal visual acuity (visus oculi dextri, 1.0 diopter [D], visus oculi sinistri [VOS], $1.0 \mathrm{D}$ ), and normal intraocular pressure (normal range, 12 to $22 \mathrm{mmHg}$ ). But the patient kept complaining of pain and painkillers were ineffective. We reviewed the CT scan of the brain, and observed lens subluxation in the left eye (Fig. 3). So we consulted to ophthalmologist again. It revealed protrusion of the vitreous body into the anterior chamber, posterior subcapsular opacity, phacodonesis, and lens subluxation toward the nasal area of the left eye, and the ophthalmologist decided him to out-patient department follow up for the possibility of operation.

Spontaneous zonulysis of the left eye was diagnosed. The symp-

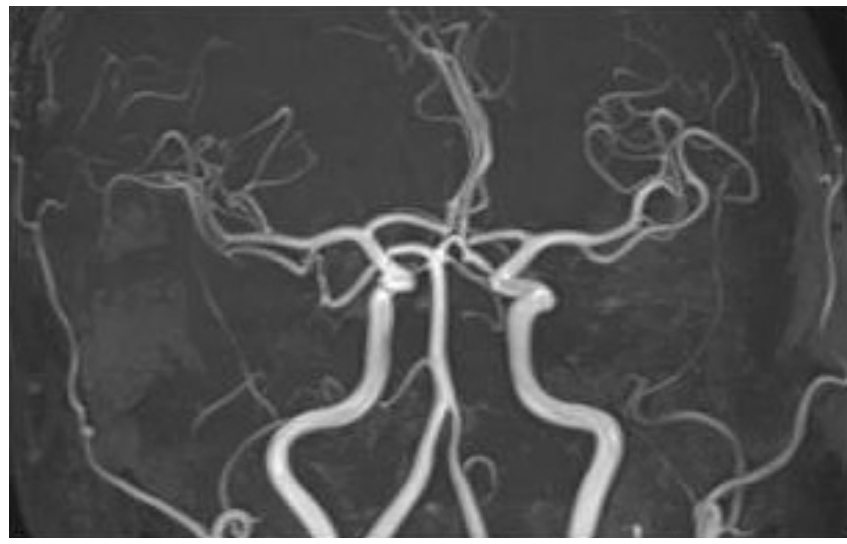

Fig. 2. No evidence of abnormal aneurysmal dilatation and arteriovenous fistula on brain magnetic resonance angiography. 


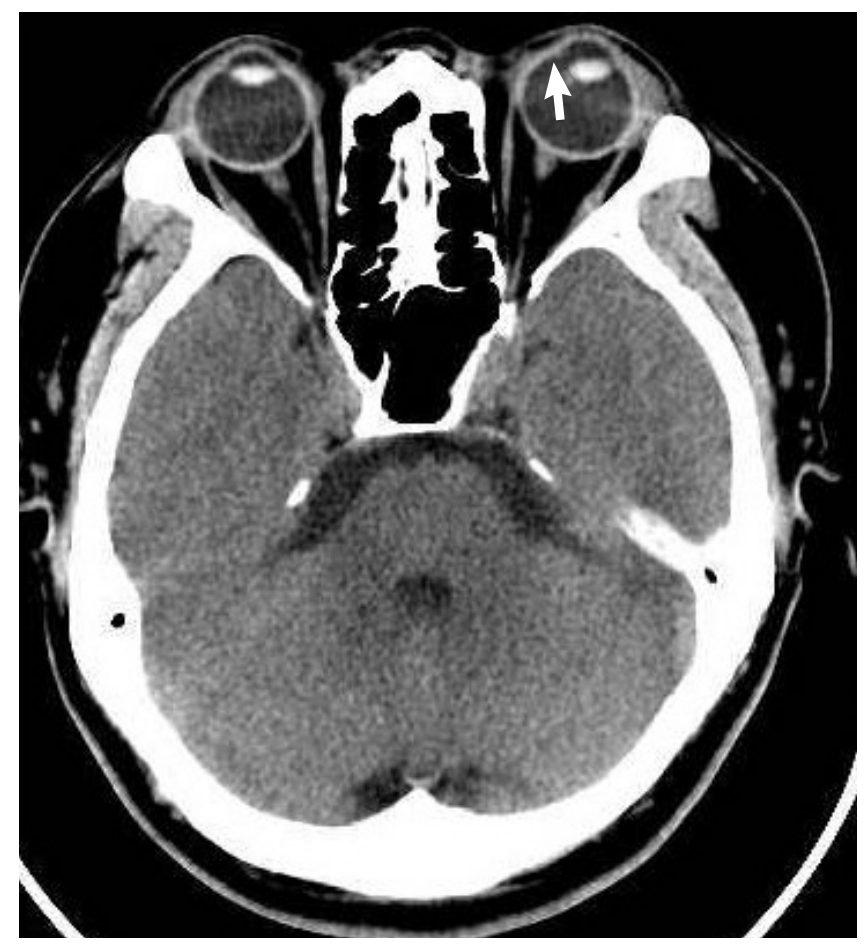

Fig. 3. Left lens subluxation due to zonulysis in the nasal area. Arrow shows displacement of the lens.

toms were attributed to a temporary pupillary block and angle closure glaucoma attack. So we recommended him to visit outpatient department and explained the possibility of laser iridectomy in case of aggravation of disease.

After 3 days, he visited the ophthalmologic out-patient department, and initial examination showed fluctuation of vision scale (initial exam VOS 0.1 D; after 1hour exam VOS 0.9 D) in left eye. The intraocular pressure was normal but slit lamp examination revealed further prolapse of the vitreous body into the anterior chamber.

There was more progressive inferior dislocation of left lens due to zonulysis in dilated funduscopic examination otherwise normal finding in right eye (Fig. 4). The patient was discharged and an operation was scheduled for 2 days later.

After 2 days, the left eye had been rendered aphakic because of complete dislocation of the lens. Left pars plana vitrectomy (PPV) and intra ocular lens (IOL) fixation were recommended by the ophthalmologist. However, the patient wanted to undergo the operation in his hometown and hence, was discharged.

\section{DISCUSSION}

The reported causes of dislocation of the crystalline lens of the eye include trauma, heredity, and spontaneous occurrence. ${ }^{2,3}$

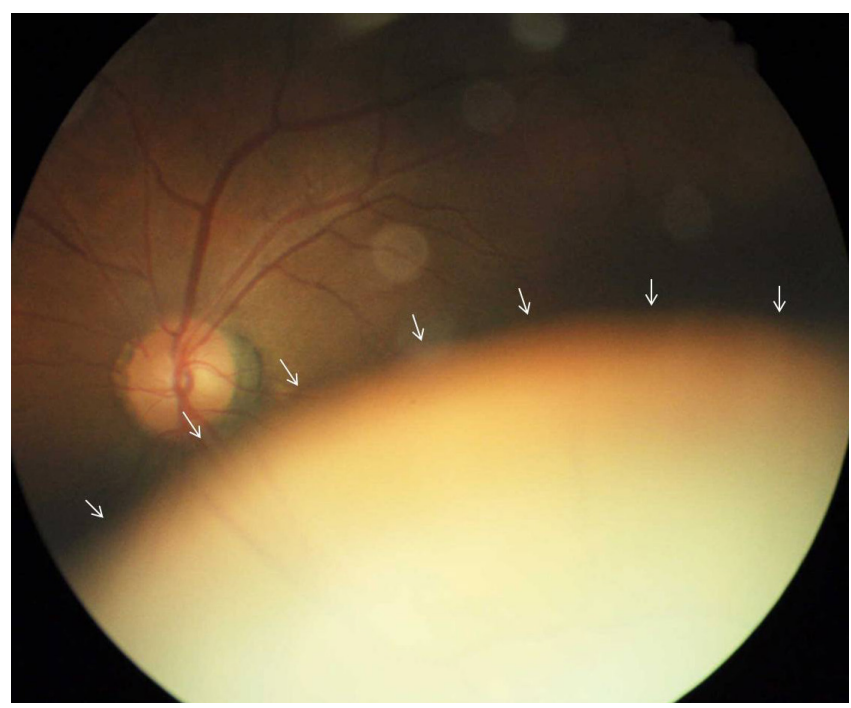

Fig. 4. Inferior subluxation of the left lens, as revealed in dilated funduscopic examination. Arrow shows displacement of the lens.

Among these, the most common cause of lens luxation is trauma (include ophthalmological operation). ${ }^{4}$

However, in our case, the patient had no history of trauma, nor were there any symptoms or signs of trauma.

Hereditary forms of lens dislocation have been associated with other systemic anomalies (eg, Marfan syndrome, homocystinuria, and Weill-Marchesani syndrome). ${ }^{5}$ Among them, Marfan syndrome is the most common. Lens dislocation occurs in about 75\% of the patients with Marfan syndrome and is usually bilateral, symmetrical, and supertemporal. ${ }^{6}$ However in our case the patient had no recurrence on the contralateral side for 2 years, and showed no salient features of Marfan syndrome including tall stature, arachnodactyly, joint laxity, mitral valve prolapse, aortic dilatation, axial myopia, increased incidence of retinal detachment, etc.

The second most common cause of hereditary lens dislocation is homocystinuria. This disease is an inborn error of metabolism with an early age of onset which does not fit in our case. Additionally, the patient had no history or symtoms of homocystinuria. According to literature, in homocystinuria, the lens is classically displaced either inferiorly or inferonasally, which was the case with our patient; however, the average age of homocystinuria patients is below 30 years, which is far below our patients age. $^{7}$

In Weil-Marchesani syndrome, the lens is usually displaced inferiorly. It occurs in children and patients who have skeletal malformations including short stature, brachycephaly, limited joint mobility, and well-developed muscular appearance. These features were not observed in our patient. ${ }^{8}$

Therefore, it is hard to assume that systemic anomaly caused 
the lens dislocation in the case of our patient.

This case was one of spontaneous dislocation of the lens with luxation into the vitreous cavity, a very unusual and rare occurrence.

Unilateral headache with ophthalmalgia can have several other causes such as cluster headache, glaucoma, Tolosa-Hunt syndrome, cavernous carotid fistula, etc. This case was caused by lens dislocation and movement because of change in the patient's position. The lens was positioned normally when the patient was sitting; however, in the supine position (for example, for CT), the lens underwent dislocation.

Generally, we tend to more carefully read a brain parenchyma as reading a brain $\mathrm{CT}$ than the other anatomical lesion including orbital lesion. However, as in this case, we should review area other than brain parenchyma carefully, not to miss the important findings.

\section{CONFLICTS OF INTEREST}

No potential conflict of interest relevant to this article was reported.

\section{REFERENCES}

1. Jovanovic M. Bilateral spontaneous crystalline lens dislocation to the anterior chamber: a case report. Srp Arh Celok Lek 2013;141:800-2.

2. Kanski J, Bowling B, Nischal KK, Pearson A. Clinical ophthalmology: a systematic approach. New York: Elsevier/Saunders; 2011.

3. Pop R. Spontaneous luxation of the crystalline lens into the anterior chamber (a clinical case report). Oftalmologia 1992; 36:61-3.

4. Soler VJ, Leray B. Post-traumatic lens dislocation presenting as an eclipse in a patient demonstrating monocular blindness secondary to post-traumatic glaucoma. J Fr Ophtalmol 2014; $37: 423$.

5. Miraldi Utz V, Coussa RG, Traboulsi El. Surgical management of lens subluxation in Marfan syndrome. J AAPOS 2014;18: 140-6.

6. Ganesh A, Smith C, Chan W, et al. Immunohistochemical evaluation of conjunctival fibrillin-1 in Marfan syndrome. Arch Ophthalmol 2006;124:205-9.

7. Hafidi Z, Berradi S, Handor H, Regragui A, Lezrek M, Daoudi R. Atypical presentation of ectopia lentis in homocystinuria. J Pediatr 2015;166:1091.

8. Wentzloff JN, Kaldawy RM, Chen TC. Weill-Marchesani syndrome. J Pediatr Ophthalmol Strabismus 2006;43:192. 